\section{Um estudo variável do rótico na escrita escolar}

A variable study of the rotic in school writing

André Pedro da SILVA (UFBA) pedroufpb@gmail.com

Layanne Alves Lopes DIAS (UFRPE)

layanne.letras@gmail.com

Recebido em: 15 de maio de 2020. Aceito em: 15 de junho de 2020.

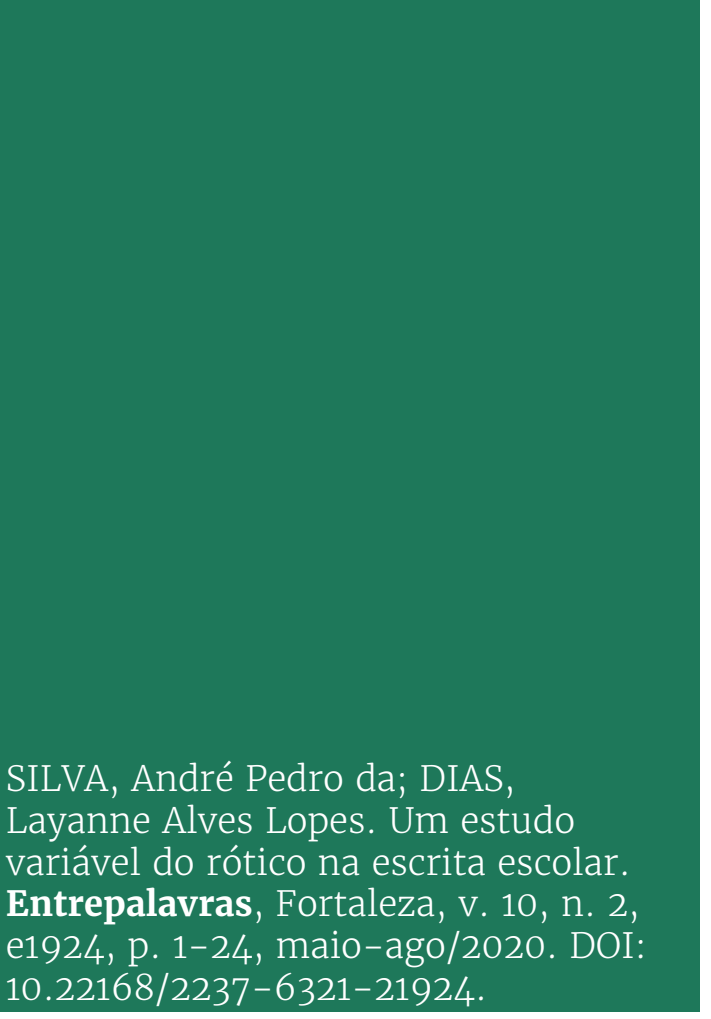

Resumo: A língua escrita possui grande relevância sociocultural, pois grande parte das esferas da atividade humana se organiza por meio do seu uso. Considerando essa importância e a necessidade de escrever atendendo às convenções ortográficas, este trabalho objetiva investigar a escrita do rótico em posição de coda silábica (medial e final) na escrita de alunos do ensino fundamental de um colégio privado, da cidade de São Loureço da Mata - PE. Aqui, objetivamos analisar o apagamento do rótico em coda silábica, na escrita ortográfica, advinda da oralidade e, para tanto, verificamos os possíveis gatilhos para o processo em questão. Tomamos como pressupostos teóricos os trabalhos de Bisol (2009), Cagliari (2002), Callou, Moraes e Leite (1998), Cardoso et al. (2014), Costa (2009), Faraco (2006), Garcia (2010), Miranda (2010), Mollica (2003), Signorini (2001), Tasca (2002) e Vegini (2007). O corpus dessa pesquisa se constituiu de ditados ortográficos, tomando por base o método indutivo e consecutiva análise quantitativa desses dados. Destarte, foi possível a apropriação de material que nos permite conjecturar sobre a heterogeneidade da escrita, pois identificamos que os "erros" ortográficos 
V. $10(2)$

$1-24$

maio-ago

2020

dos estudantes são, na maioria, advindos do fato de que há vazamento de processos do campo fonológico para o campo da escrita. Os resultados apontam que o apagamento diminui com o aumento da escolaridade, pois, dentre as 440 palavras analisadas, ocorreu apagamento 98 vezes no $6^{\circ}$ ano e 35 no $9^{\circ}$ ano. Cabe ressaltar ainda que ambas as turmas variaram mais as palavras em que o rótico estava em posição de coda medial.

Palavras-chave: Desvios Ortográficos. Rótico. Oralidade e Escrita.

Abstract: The written language has great sociocultural relevance, since most of the spheres of human activity are organized through its use. Considering this importance and the need to write in accordance with orthographic conventions, this work aims to investigate the writing of the rhotic in a syllabic coda position (medial and final), in the writing of elementary school students from a private school, in the city of São Lourenço da Mata - PE. Here, we aim to analyze the erasure of the rhotic in syllabic coda, in orthographic writing, arising from orality and, therefore, we check the possible triggers for the process in question. We take as theoretical assumptions the works of Bisol (2009), Cagliari (2002), Callou, Moraes and Leite (1998), Cardoso et al. (2014), Costa (2009), Faraco (2006), Garcia (2010), Miranda (2010), Mollica (2003), Signorini (2001), Tasca (2002) and Vegini (2007). The corpus of this research consisted of orthographic dictations, based on the inductive method and consecutive quantitative analysis of these data. Thus, it was possible to appropriate material that allows us to conjecture about the heterogeneity of writing, as we identified that the students' orthographic "errors" are, in the majority, due to the fact that there is leakage of processes from the phonological field to the writing field. The results show that the erasure decreases with the increase in schooling, because, among the 440 words analyzed, erasure occurred 98 times in the 6th grade and 35 in the 9th grade. It is also worth noting that both classes varied more the words in which the rhotic was in a medial coda position.

Keywords: Orthographic Deviations. Rhotic. Orality and Writing.

\section{Introdução}

Os estudos linguísticos já mostraram que não podemos conceber a língua como um sistema homogêneo, pois esta é ferramenta de interação social e suas múltiplas representações são resultados das diversas relações humanas. A realização do rótico na Língua Portuguesa (LP) no Brasil está condicionada não só a contextos linguísticos, mas também a fatores sociais. Contudo, por mais que as pesquisas linguísticas tenham trazido à tona certas relações entre a língua e a sociedade, é possível perceber ainda que, no ambiente escolar, o ensino ainda é pautado em correções, considerando como "erro" - já grafado entre aspas por Massini-Cagliari (1999) - certos usos deste realizado pelos alunos.

Uma das dificuldades mais comuns na comunidade escolar é entender as várias formas de realização na escrita, advinda da oralidade, do fonema /R/, uma vez que existem até oito maneiras de realização

\footnotetext{
${ }^{1}$ Para esse trabalho, tomamos a palavra "erro" como aquela escrita fora dos padrões ortográficos da Língua Portuguesa.
} 
dos róticos no português falado no Brasil. Segundo Bisol (2009), são eles: [ג] retroflexo, [r] tepe, [h] glotal surda, [H] glotal sonora, [x] velar surda, $[\gamma]$ velar sonora, $[r]$ alveolar e o [ $\emptyset]$ zero fonético. Assim, este artigo seguirá pautado a partir de um olhar inspirado nas teorias da sociolinguística e da fonologia, tendo em vista que:

uma questão que desde sempre tem preocupado os professores e estudiosos de alfabetização diz respeito a como lidar com os chamados "erros" de ortografia. Uma das possíveis maneiras de se lidar com eles é considerá-los como uma escrita fonética, manifestação de desejo de transcrever a fala tal como ela se realiza. (MASSINI-CAGLIARI, 1999, p. 121, grifos nossos)

Para tanto, segue-se aqui a ideia de Miranda (2006;2010), segundo a qual em se tratando de aprendizagem das normas gramaticais, o "erro" é parte do processo pelo qual o escrevente passa quando tenta alcançar a norma culta, e que não há interferência (no sentido pejorativo da palavra) da oralidade na escrita, uma vez que a língua é heterogênea. Dessa maneira e dentre as diversas variações que ocorrem na nossa língua, nosso recorte volta-se para a realização (ou não) do rótico na escrita, isto é, verificamos, na escrita de alunos de ano inicial $\left(6^{\circ}\right)$ e do ano final $\left(9^{\circ}\right)$ do Ensino Fundamental (EF) II, de um colégio particular da cidade de São Lourenço da Mata-PE, como o rótico se apresenta, atentando-nos para seu apagamento ou manutenção quando em posição de coda medial e final.

Dessa forma, este artigo tem como objetivos analisar a ocorrência do fenômeno linguístico de apagamento do rótico na escrita dos estudantes do EF II, de uma escola privada, localizada na Região Metropolitana do Recife-PE; detectar os fatores linguísticos e sociais responsáveis por esse processo em ambiente escolar, nos alunos de $6^{\circ} \mathrm{e}$ $9^{\circ}$ anos do ensino fundamental; observar se o fenômeno de apagamento acontece mais na coda final ou na coda medial das palavras; do mesmo modo, qual a classe gramatical mais propícia para o apagamento, se em verbos ou não-verbos; bem como verificar se o fenômeno diminui com o avanço da escolaridade; por fim, verificar se suas rotinas de letramento interferiam na aquisição da norma ortográfica da língua escrita, através de um questionário de hábito de leitura e de escrita ${ }^{2}$, a fim de se testar, quantitativamente, o uso da variação na escrita escolar, tomando por base a frequência de leitura e de escrita daqueles alunos.

${ }^{2}$ Questionário padrão para todas as pesquisas realizadas pelo grupo REFALES, ao qual integramos. 
V. $10(2)$

$1-24$

maio-ago

2020

Para análise dos dados, além dos resultados obtidos, fizemos uso de porcentagens, o que nos proporcionou informações muito importantes sobre o fenômeno em estudo.

Há, na literatura, uma vasta pesquisa a respeito do apagamento do rótico na oralidade, entretanto esse material apresenta-se em menor quantidade no tocante à escrita. E mesmo alguns trabalhos já existentes, como os de Costa (2009), Ribeiro (2013) e Sene e Oranges (2017), são muito pontuais, tratando do rótico na escrita escolar de Catu-BA, Salvador-BA e Uberaba-MG, respectivamente. Isto posto, sentimos a necessidade de fazer uma investigação voltada para a nossa localidade, a fim de expandir as pesquisas sobre o tema em questão.

\section{A apropriação da escrita a partir de vazamentos da fala: a variação linguística}

Com intenção de compreendermos como ocorre a aquisição das convenções ortográficas por parte dos estudantes do ensino regular, primordialmente se faz necessário que consideremos o processo de aprendizagem da mesma. Nesse sentido, inevitavelmente, o aprendiz vai passar por "erros" e/ou "desvios" à norma padrão. O que convém ressaltar, no entanto, é o que esse "erro" representa, isto é, o seu significado dentro desse processo. De acordo com Miranda (2010, p. 3):

para alguns o erro é sinônimo de não-acerto e, portanto, de não-aprendizagem; para outros, ao contrário, é elemento revelador do processo de aprender. Nesse último sentido, a concepção de erro converge para a definição freireana segundo a qual o erro é uma forma provisória de saber e nos remete a noção de 'erro construtivo' que se filia às idéias de Piaget.

Assim sendo, a partir dos "erros" podemos identificar as experiências linguísticas do escrevente.

Sabendo, então, que, via de regra, esses "erros" são ocasionados pelo fato de que o aprendiz tenta refletir na escrita estruturas que são típicas da fala, tais como a segmentação de palavras em dois vocábulos ("com" e "migo" ao invés de "comigo", por exemplo), o apagamento das semivogais em ditongos ou ainda do rótico em posição de coda ("caxa" ao invés de "caixa" e "iogute" ao invés de "iogurte"), que são processos fonéticos ilustrativos da variação linguística, Miranda (2006) denomina essas "interferências" da fonética no processo de escrita como vazamentos linguísticos. 
Essa reflexão muito se assemelha aos resultados dos estudos sociolinguísticos de Labov (2008 [1972]), os quais entendem a língua como variável de acordo com o meio social, pois se tanto língua quanto sociedade são sistemas que podem apresentar heterogeneidade, a heterogeneidade na sociedade pode provocar heterogeneidade dentro da língua e vice-versa.

À vista disso, concordamos que a língua não é uniforme e, ainda que em sua forma escrita haja um padrão definido pelas convenções gramaticais, em se tratando do quesito oralidade, ela apresenta inúmeras variações, seja de ordem fonética, com alofonias; seja de ordem morfológica, sintática ou semântica, cujos exemplos são vários: (a) quando se marca o plural apenas no determinante da frase ${ }^{3}$; (b) quando se usa pronome oblíquo átono no início de sentenças ${ }^{4}$; etc. Diante disso:

possibilitar momentos de reflexão sobre o tema exposto é uma necessidade para que as variantes linguísticas deixem de ser, preconceituosamente, observadas e passem a ser consideradas objeto de estudo, inclusive, facilitadoras da aprendizagem linguística. (SGARBI; RONCÁLIA, 2009, p. 2)

Assim sendo, reconhecendo que a fala exerce influência no processo da escrita, torna-se importante reconhecer os processos fonológicos variáveis dentro da escrita dos estudantes. Além disso, instaura-se uma certa apatia por parte dos aprendizes, devido ao fato de as variantes por eles utilizadas não serem aceitas, nem valorizadas dentro de um sistema linguístico, já que divergem das convenções ortográficas. No entanto, devemos considerar que:

sempre que se fala em formas corretas de língua não se está tratando de alguma qualidade intrínseca a tais formas que faria delas algo melhor que as demais. O que estabelece a correção são valores positivos que, por razões políticas e/ou culturais, são agregados a certas formas e não a outras. Assim, do ponto de vista estrutural [...] todas as formas e variedades linguísticas são equivalentes. [...] Isso significa dizer que todas as formas e variedades linguísticas têm uma organização estrutural (uma gramática), embora só algumas recebam a qualificação de corretas. (FARACO, 2006, p. 17, grifos nossos)

Por conseguinte, alinhamo-nos aos pressupostos da sociolinguística educacional, que "atentando a estas variações da fala

\footnotetext{
3 Exemplo: "A $\underline{\mathbf{s}}$ roupa já está seca."

4 Exemplo: "Te amo!"
} 
V. $10(2)$

$1-24$

maio-ago

2020

que, às vezes, são transpostas para a escrita", de acordo com Garcia (2010, p. 16) tem como foco "o exame dos vários fenômenos da variação linguística, característicos do Português Brasileiro (PB), analisados em suas implicações para o processo de ensino-aprendizagem, principalmente no Ensino Fundamental".

Isto posto, na subseção seguinte, iremos abordar o rótico e sua variação, objeto primeiro desta pesquisa.

\section{O fenômeno linguístico de variação do rótico}

De forma elementar, denominamos rótico quando o fonema /R/ vem em posição pós-vocálica, e este é um fonema que se realiza de maneira bastante variável, uma vez que,

Do ponto de vista geral, o r é produzido pela ponta ou dorso da língua contra a arcada dentária superior ou contra os alvéolos, ou ainda contra o véu palatino, por pequenas oclusões. A língua pode não fechar totalmente a passagem do ar, fazendo desaparecer a vibração e dando lugar a um som fricativo ou aspirado, muito comum nas línguas. [...] Há outros sons de r, como o de uma batida da ponta da língua junto aos alvéolos, chamado de r-fraco ou tepe. Existe também o retroflexo, em que se levanta e se encurva a ponta da língua em direção à região palato-alveolar ou mesmo palatal. (MONARETTO, 2009, p. 141)

Esse fenômeno pode assumir, na fala, sete formas distintas ou ainda ocorrer como o zero fonético quando há o seu apagamento. Em vista disso, o rótico tem sido objeto de vários estudos em diferentes regiões do Brasil e esses estudos, em sua maioria, contemplam apenas a variação no âmbito da oralidade, como, por exemplo, o oportuno material oferecido pelo Atlas Linguístico do Brasil (2014).

Chamamos a posição final pós-vocálica, referida por Costa (2009) no parágrafo anterior, de coda, que pode ser medial ou final a depender da posição da sílaba na palavra. A exemplo do fonema /r/ em posição de coda, temos "ser.ven.te" e "ca.ça.dor $\underline{\text { r", }}$ respectivamente coda medial e coda final, quando, nestas posições, o 'erre' causa o travamento silábico e tende a ser cancelado na oralidade, numa tendência de simplificação da estrutura silábica. Podemos comprovar isso através dos resultados obtidos por Callou, Moraes e Leite (1998, p. 36), que apontam para o episódio de que:

Em posição final de coda, onde o apagamento é observado, sua variação articulatória, como se pode ver [...], vai de uma 
vibrante, alveolar ou uvular, a uma fricativa, velar ou glotal, chegando a seu total apagamento. [...] Assim, o comportamento do R em final de vocábulo deve ser analisado separadamente, uma vez que a posição final (externa) constitui o ambiente onde o apagamento se dá mais frequentemente.

Uma vez que a coda teria uma posição fraca na sílaba, "pode ser interpretada como um lugar de virtuais variações na língua, o 'lugar fonológico' em que poderá ocorrer, em princípio, um grande número de alofonias na fala e o 'lugar' de um grande número de variações de escrita" (ALVARENGA; OLIVEIRA, 2019, p. 131). Destarte, esse 'erre' que se apresenta como zero fonético vaza para escrita e interfere no aprendizado da norma culta da língua dos escreventes.

Outrossim, Mollica (2007) já alertava para o fato de que essa variação na fala não é estigmatizada, quer dizer, quem, por exemplo, fala sevente "não recebe avaliação negativa" (p. 48) - ao contrário do que acontece com quem pronuncia probrema. O falante, não recebendo "censura", apreende que essa é a forma correta da palavra, tanto no campo da oralidade quanto na escrita. Por isso que "o cancelamento da vibrante pós-vocálica" é um dos "fenômenos fonológicos que merecem trabalho pedagógico voltado para a escrita" (MOLLICA, 2007, p. 47).

Compete, assim, ao professor fazer essa correção quando ela sai do campo fonético e passa a manifestar-se na escrita dos estudantes. Em vista disto, é necessário que os professores tenham consciência dos processos fonológicos, posto que, ao pensar na relação oral/escrito, a heterogeneidade é, segundo Corrêa (2001, p. 144), "constitutiva da escrita, e não uma característica pontual e acessória desta". Assim sendo, deverá ser considerado o processo de produção e aquisição da escrita, pois, quando se compreende por que o desvio às convenções gramaticais está ocorrendo, torna-se mais fácil a sua correção. Passemos, então, à explanação acerca da metodologia utilizada para a realização dessa pesquisa.

\section{Percurso metodológico}

Para a execução desse trabalho foi realizada uma pesquisa bibliográfica sobre a teoria da variação linguística, tomando por base os trabalhos de Callou, Moraes e Leite (1998), Cardoso et al. (2014), Costa (2009), Garcia (2010), Labov (2008), Miranda (2010), Mollica (2003), Tasca (2002) e Vegini (2007), levando em conta questões teóricometodológicas, bem como análises já realizadas sobre a variação linguística em dados de fala e de escrita no Português Brasileiro. 
V. $10(2)$ $1-24$ maio-ago 2020
A fim de realizar a coleta do material que foi utilizado como corpus dessa pesquisa, escolhemos um colégio particular localizado em São Lourenço da Mata, pois as pesquisas que contemplam a mesma temática que a nossa são realizadas, em sua grande maioria, em instituições de ensino da rede pública, e, com isso, pretendemos ampliar as discussões sobre o fenômeno, evidenciando sua ocorrência também no ambiente de ensino particular. Desse colégio, participaram 53 estudantes, sendo 23 alunos da turma do $6^{\circ}$ ano do EF II e os outros 30 da turma do $9^{\circ}$ ano, também do EF II.

Para iniciarmos a pesquisa e, consequentemente, a coleta de dados, houve um prévio contato com os diretores da escola e com o professor de Língua Portuguesa, com o propósito de solicitar-lhes a permissão para que os estudantes pudessem participar dos treinos ortográficos que resultaram no corpus de nossa pesquisa. Além disso, também foi necessário marcar uma reunião com os pais dos estudantes para que explicássemos detalhes da pesquisa, para que estes assinassem o Termo de Consentimento Livre e Esclarecido - TCLE, uma vez que os estudantes eram menores de idade.

Essa pesquisa tem respaldo do Comitê de Ética da Fundação Joaquim Nabuco, sendo autorizado por meio do Parecer Consubstanciado CAAE: 67297517.0.0000.5619, versão 2, seguindo todas as suas prerrogativas. Isso implica na utilização das produções que foram devidamente autorizadas pelos responsáveis legais dos alunos pesquisados, por se tratarem de menores de idade, no seu anonimato e no da escola.

Após a coleta dos dados, tivemos, para efeito de análise, que equiparar o número de estudantes entre as turmas. Assim, foi considerado apenas o material de 22 alunos de cada ano escolar. Para isto, usamos dois critérios para identificar quais os materiais que seriam avaliados nessa pesquisa. Foram eles: (a) a devolução do Termo de Consentimento Livre e Esclarecido; e (b) caligrafia, posto que foi primordial para nossa análise que os estudantes escrevessem de forma legível para que pudéssemos identificar a presença ou a ausência do rótico nos vocábulos.

Foram analisados, então, treinos ortográficos produzidos por alunos de anos iniciais e finais do EF, no intuito de testar a hipótese norteadora desta pesquisa: os dados de escrita estão mais próximos da fala e, na medida em que se dá o letramento, com o aumento da escolarização, tendem a se afastar desta. 
O ditado ortográfico dividiu-se em dois níveis ${ }^{5}$ de coletas de dados: (a) ditado de palavras e (b) ditado ortográfico de frases (no qual cada aluno teria que preencher uma lacuna em uma frase dada), para que fosse testado o momento de atenção. Eles foram pensados a partir de Mollica (2003, p. 28), que criou um teste que "constitui-se de frases onde as crianças deveriam, seguindo os ícones, preencher as lacunas adequadamente". Assim, foi possível "o controle das variáveis selecionadas como importantes para o cancelamento do segmento travador de sílaba, conforme os estudos voltados para a fala" (MOLLICA, 2003, p. 28). Além disso, a escolha desse procedimento metodológico também foi devido ao fato de que, se solicitássemos que os estudantes escrevessem textos espontâneos, não teríamos como controlar a seleção lexical dos mesmos. Dessa forma, seria difícil, quiçá inexequível, o controle das variáveis.

As palavras utilizadas nesse estudo formaram dois grupos. Priorizamos, nesta pesquisa, palavras mais usuais no dia a dia dos alunos, sem levarmos em consideração quaisquer elementos linguísticos, formando assim os seguintes grupos:

- Grupo A (erre em posição de coda medial): morcego / observar / perceber / percevejo / perseguir / personagem / preservar / reforçar / servente / sorvete

- Grupo B (em posição de coda final): andar / arrumar / caçador / celular / confessar / escrever / monsenhor / precisar / protetor / ventilador

Vale ressaltar que, como nosso estudo objetiva fazer uma análise contrastiva entre o apagamento em posição medial x final, mesmo algumas palavras do Grupo A apresentando tanto o erre em posição medial quanto final, só foram considerados, para efeito de análise, os erres destacados.

De mais a mais, cada grupo foi formado por cinco palavras verbos e outras cinco não-verbos (nomes), tendo em vista que um dos nossos objetivos era identificar qual classe gramatical é mais favorável ao fenômeno de apagamento.

Outrossim, em data previamente combinada com o professor do colégio, os estudantes responderam também a dois questionários, um informando a respeito dos seus hábitos de leitura, e outro sobre os

${ }^{5}$ Para ambos os níveis, foi utilizada a mesma seleção de palavras. 
V. $10(2)$ $1-24$ maio-ago 2020

hábitos de escrita, a fim de que pudéssemos verificar se suas rotinas de letramento interferiam na aquisição da norma ortográfica da língua escrita.

Realizada a coleta desses materiais, foi feita a análise quali-quantitativa desses dados, tomando por base a metodologia de abordagem indutiva e de procedimento estatístico, visando identificar a frequência de apagamento do rótico, bem como os fatores responsáveis por tal fenômeno, material que poderá ser observado na próxima seção.

\section{Resultados e discussão}

Quando nos propusemos a investigar as relações entre a oralidade e a aquisição da escrita em ambiente escolar, precisamos considerar que o aprendizado das convenções ortográficas é interpretado, sobretudo, através de dois vieses: um levando em consideração que esse aprendizado vai partir primeiramente da escrita fonética, isto é, que o estudante transcreve a forma oralizada que escuta; e o outro, da escrita ortográfica, aquela que é "resultado de uma reflexão produtiva (e construtiva) a respeito de fatos do próprio sistema de escrita com o qual está começando a lidar" (MASSINI-CAGLIARI, 1999, p. 121). No entanto, vale salientar que:

tanto a escrita fonética como a ortográfica possuem como ponto de partida para representação das palavras a observação dos sons da fala, [assim] o aprendizado de um sistema ortográfico passa, inevitavelmente, por questões de representação típica da escrita fonética. (MASSINI-CAGLIARI, 1999, p. 127)

E é sobre essas representações fonéticas no processo de aquisição da escrita "padrão" que nos debruçamos neste trabalho.

Partimos, então, do pressuposto de que éindubitável o fenômeno do apagamento do rótico na linguagem oral, como verificado no Atlas Linguístico do Brasil - ALiB (cf. CARDOSO et al., 2014, p. 100-110). No ALiB, é perceptível que o apagamento do /R/, na oralidade, ocorre mais expressivamente em posição de coda final. Percebe-se, por exemplo, que, nos resultados referentes à Recife-PE, os valores se invertem totalmente quando contemplamos a presença versus ausência no tocante à posição do rótico em coda externa (quase sua totalidade em ausência) vs coda interna (que encontra sua quase totalidade na presença). No entanto, não podemos deixar de considerar que, embora em menor frequência, esse fenômeno ainda estende-se à posição de coda medial. 
Ainda em conformidade com os dados do ALiB, torna-se notório que a ausência do rótico em posição de coda final (Gráfico 1) só é medida em relação aos verbos, desconsiderando, assim, a ocorrência desse fenômeno em não-verbos (nomes).

É importante mencionar que, em nossos dados, houve uma palavra que se destacou pelo fato de só sofrer o apagamento uma única vez: a palavra "celular". Acreditamos que isso se deve ao nível de familiaridade que os estudantes já possuíam com ela. Costa (2009) já havia identificado isso em suas investigações e concluiu que:

há uma diferença significativa, com um aumento considerável de cancelamento do segmento - $\mathrm{r}$ - nas palavras que foram consideradas menos frequentes na escrita escolar do aluno, o que confirma a nossa hipótese de que palavras com menor familiaridade favoreceriam o apagamento do r. (COSTA, 2009, p. 142)

Prosseguindo, chegamos a um resultado bastante interessante e peculiar, já que nas palavras que mais sofreram o fenômeno de apagamento, o som rótico se encontrava em posição medial. E isso é antagônico ao que a maioria das pesquisas vinha apontando até então, tal como pôde ser observado no ALiB ou nos apontamentos de Toledo (2009, p. 413), que, em sua pesquisa no litoral do Paraná, destaca que "o apagamento ocorre nos três grupos indistintamente [...], sempre em coda silábica externa".

A respeito disso, conjecturamos que há uma tendência crescente em relação ao apagamento do / $\mathrm{R} /$ em coda medial, o que não ocorre mais com o /R/ em posição final, tendo em vista que "o apagamento do /R/ final segue o padrão gradação etária e 'tem sido considerado um caso de mudança de baixo para cima que, ao que tudo indica, já atingiu seu limite, e é hoje uma variação estável, sem marca de classe social'" (CALLOU et al. apud VEGINI, 2007, p. 6).

Detectou-se também nas palavras do Grupo B, aquelas que nos competiu analisar o apagamento do 'erre' final, que houve mais variação no grupo de verbos, uma vez que estes sofreram apagamento 19 vezes (considerando tanto os resultados do $6^{\circ}$ ano quanto do $9^{\circ}$ ano), enquanto que, nos não-verbos, isto é, nos substantivos, os escreventes somente apagaram o erre 12 vezes, como podemos observar nos gráficos que seguem, no qual apresentamos os números de casos: 
V. 10 (2) 1-24 maio-ago 2020
Gráfico 1 - Apagamento do Rótico Final em Verbos

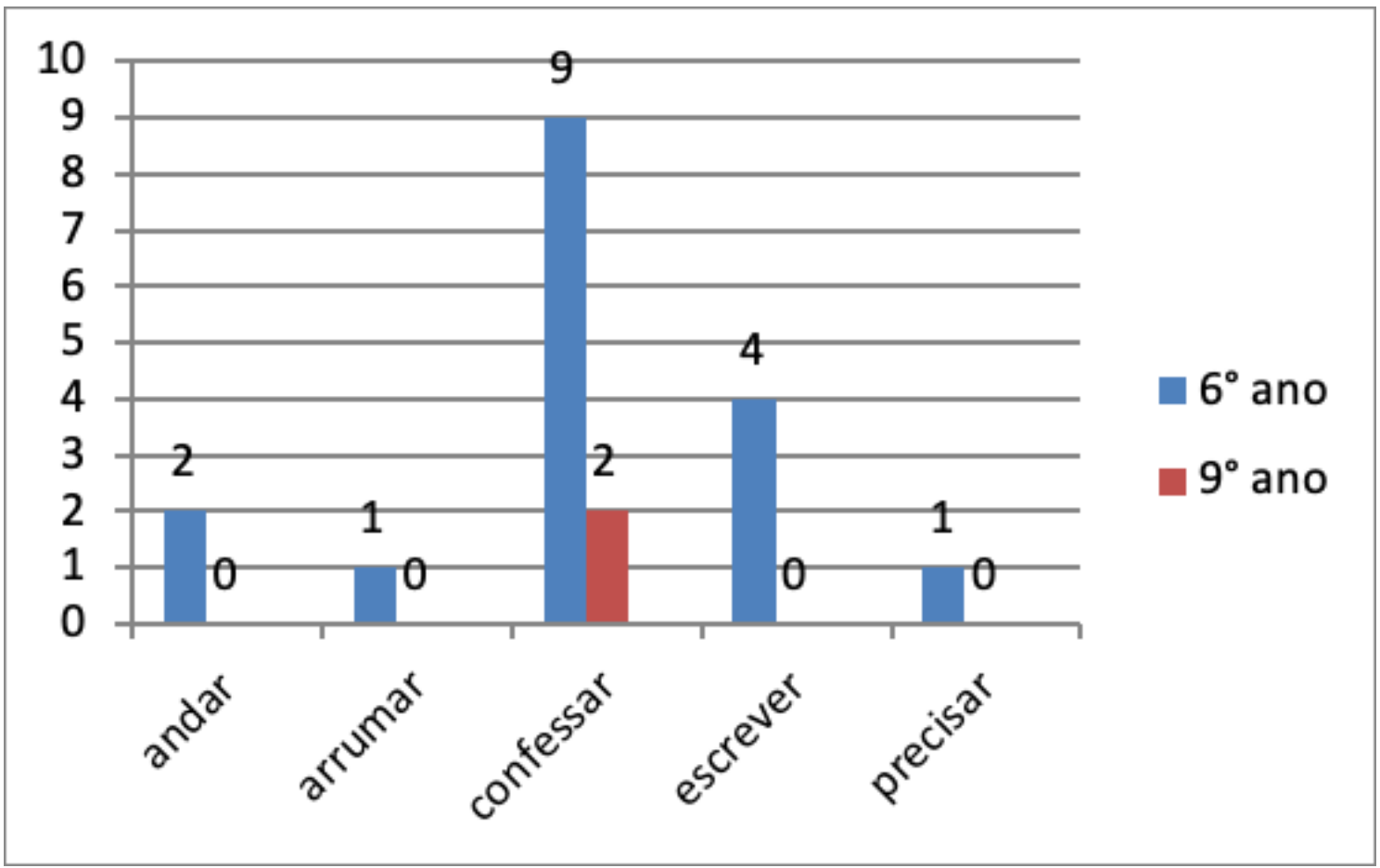

Fonte: Elaborado pelos autores.

Gráfico 2 - Apagamento do Rótico Final em Não-Verbos

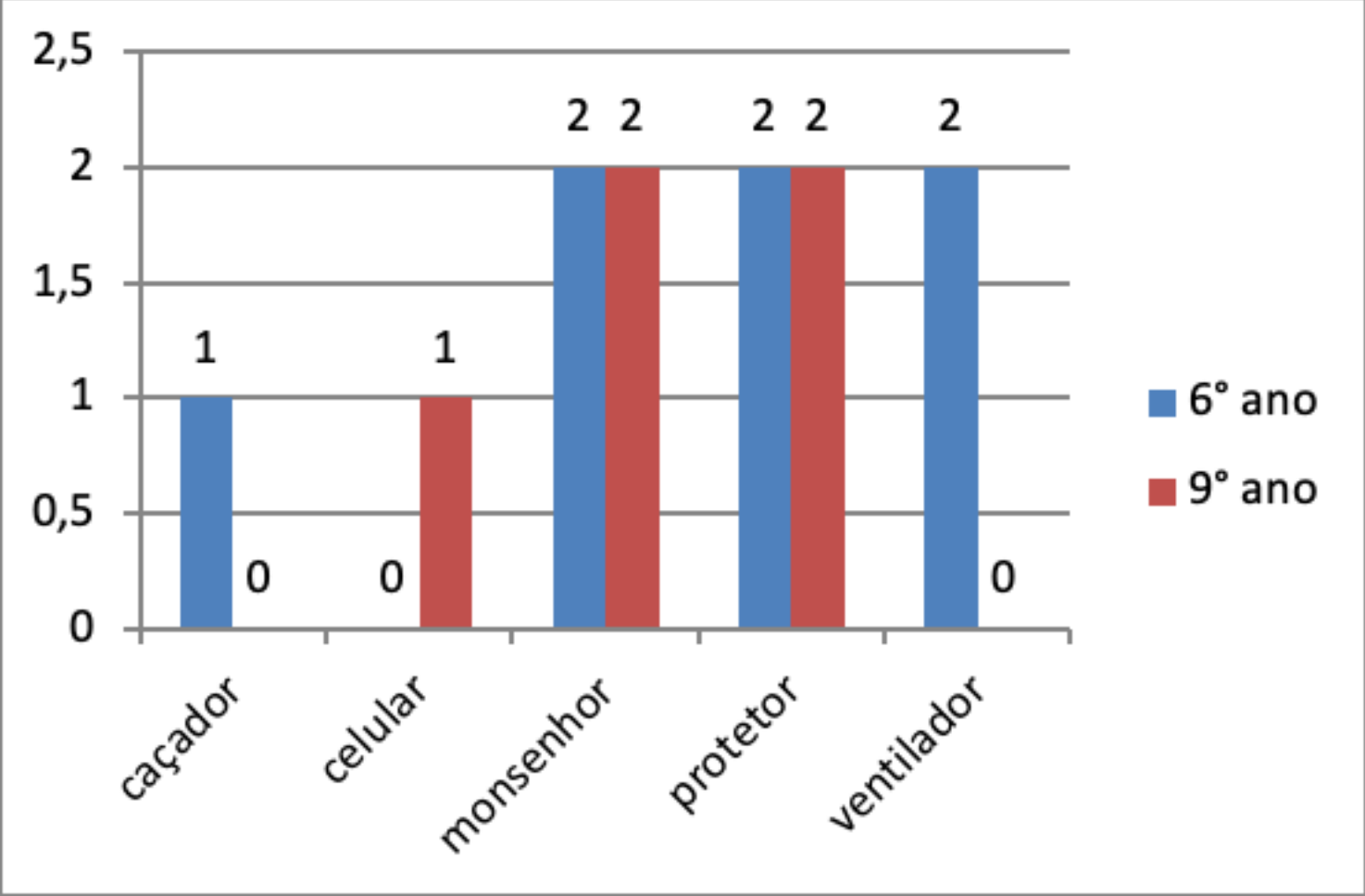

Fonte: Elaborado pelos autores. 
É curioso observar, contudo, que os verbos, mesmo sendo a classe de palavras mais propícia para o apagamento ${ }^{6}$, foi também a que apresentou melhor evolução, quer dizer, torna-se perceptível que esse fenômeno diminuiu com o avanço da escolaridade, considerando que a palavra que mais variou no Grupo B foi "confessar.", e que esta sofreu apagamento nove vezes no $6^{\circ}$ ano, mas tendo seu número reduzido para apenas dois apagamentos no $9^{\circ}$ ano, além das demais palavras que não sofreram nenhuma variação nesse ano.

Conjecturamos que esse quadro aconteça devido ao fato de que os verbos têm uma forma nominal terminada em -r, o infinitivo, além disso, a conjugação da $3^{\circ}$ pessoa do singular também seria um fator que contribuiria para o apagamento do $\mathrm{R}$ do infinitivo, pois tende a confundir os estudantes 7 . Sabendo, então, que o estudo das formas nominais dos verbos já é abordado dentro de sala de aula pelos docentes, pois faz parte de um conteúdo previsto para o ensino de nível fundamental, os escreventes tomam, assim, consciência linguística da presença do som do rótico em final de palavras, fazendo com que o processo de apagamento aqui estudado torne-se gradual, diminuindo pouco a pouco, quando em posição final.

Pontuamos também que o apagamento em não-verbos não seguiu esse mesmo padrão, já que as palavras continuaram apresentando esse fenômeno linguístico, inclusive revelando o apagamento em uma palavra que não havia variado inicialmente: a palavra "celular".

Ainda no tocante às diferenças entre os resultados obtidos com o $6^{\circ}$ e $9^{\circ}$ ano, analisando os materiais produzidos pelos escreventes, chegamos aos seguintes resultados:

- No $6^{\circ}$ ano, verificou-se 52 variações no ditado de palavras e 46 no ditado ortográfico de frases, totalizando 98 ocorrências de apagamento do rótico. A palavra que mais variou foi "perseguir" - como já explicitado na seção anterior, essa palavra pertence ao Grupo A, ou seja, só foram analisados os apagamentos do 'erre' em posição medial -, sofrendo 9 apagamentos no ditado de palavras e 7 no ditado ortográfico de frases;

\footnotetext{
${ }^{6}$ Segundo Monaretto (2002, p. 261), o apagamento do $r$ é mais recorrente em verbos "devido ao fato de que o infinitivo e a primeira e terceira pessoas do futuro do subjuntivo são redundantemente marcados em português pela presença do $r$-final e pela tonicidade. Em não verbos, por outro lado, o r-final, que não é um morfema por si só, é mais preservado".

7 Exemplificando, observe a semelhança da forma verbal "andar" nas seguintes sentenças: a. "Ela anda muito rápido!" - verbo conjugado na $3^{\circ}$ pessoa do singular.b. "É preciso andar rápido nessa área" - verbo no infinitivo.
} 
V. $10(2)$

$1-24$

maio-ago

2020

- No $9^{\circ}$ ano, verificou-se 17 variações no ditado de palavras e 18 no ditado ortográfico de frases, totalizando 35 ocorrências de apagamento do rótico; novamente, foi uma palavra do Grupo A a que mais variou: "reforçar" - 4 vezes tanto no ditado de palavras, quanto no ditado ortográfico de frases.

É válido ressaltar que a palavra com o rótico em posição final que mais variou foi "confessar", com 7 apagamentos no ditado de palavras e 2 no ditado ortográfico de frases.

Com isso, comprovamos, portanto, que a aquisição das normas ortográficas não só decorre do processo natural de aquisição da gramática, mas de um processo formal de escolarização, tendo em vista que o apagamento do rótico tende a diminuir no ano final do EF II, quando comparado às produções dos escreventes do $6^{\circ}$ ano.

Acentua-se, contudo, que o apagamento do rótico, na fala, é entendido como variação linguística. Já no tocante à escrita, é considerado "erro" ou, de uma forma mais amena, "desvio à norma culta".

Outrossim, um fenômeno que não estava inicialmente sendo avaliado por esta pesquisa chamou-nos a atenção. Houve um número elevado de hipercorreções ${ }^{8}$ durante a realização das atividades, que foram desde gestos pontuais, como a substituição do /R/ pelo acento gráfico, situação que ocorreu uma vez na palavra "preservar", grafada "presévar" por um estudante do $9^{\circ}$ ano do EF II, até mesmo um erro que foi considerado recorrente: a grafia de algumas palavras com um 'erre' a mais, como em "rerforçar", ou ainda "percevejo" com dois erres, ficando "percervejo" em 22 ocorrências, 12 em materiais do $6^{\circ}$ ano e 10 dentre os do $9^{\circ}$ ano.

Em conformidade com Corrêa (2001, p. 160), a hipercorreção indica "a tentativa de alçamento do escrevente à escrita culta", sendo "claramente uma tentativa de o escrevente legitimar-se", tornando evidente que esses "erros" derivados da hipercorreção são indícios do processo de aprendizagem pelo qual os estudantes estão passando, uma vez que, quando estes tomam conhecimento da presença do 'erre' em posição de coda, tentam a replicar essa

${ }^{8}$ Hipercorreção é o "fenômeno que decorre de uma hipótese errada que o falante realiza num esforço para ajustar-se à norma padrão. Ao tentar ajustar-se à norma, acaba por cometer um erro." (BORTONI-RICARDO, 2004, p. 28) 
informação nas demais sílabas. Fica, então, a cargo do docente de Língua Portuguesa atuar sobre o "erro", a fim de trabalhar com o aprendiz "tornando-o capaz de expressar-se em diferentes registros, de acordo com a situação de uso da língua" (TASCA, 2002, p. 19).

Seguindo na tentativa de identificar demais fatores responsáveis pelo processo de apagamento do rótico em posição coda, este trabalho também investigou as práticas de leitura dos estudantes. Passemos a elas.

\section{As práticas de leitura e sua participação no processo de aquisição da escrita ortográfica}

Um desafio que se apresenta no tocante ao ensino de língua através da vertente da sociolinguística educacional é o de como fazer para que os estudantes não apenas tomem conhecimento a respeito das variáveis presentes na linguagem, mas também assimilem que seus discursos devem ser redigidos/oralizados conforme suas intenções comunicativas. Suprimir o erre em algum texto, seja ele escrito ou falado, pode não ser um "erro" desde que o estudante tenha feito isso de maneira proposital a fim de representar algo. Os escreventes devem estudar, então, sobre a norma padrão e, de igual modo, sobre a variação linguística, já que:

as diretrizes dos sistemas de avaliação da educação básica [...] definem o domínio da chamada norma culta como a grande competência a ser alcançada pelos concluintes do ensino médio, mas o fazem isolando-a do contexto em que ela tem, de fato, sentido, ou seja, no contexto maior do domínio das práticas sociais de leitura e escrita. (FARACO, 2015, p. 20)

À vista disso, esse trabalho se propôs também a analisar de qual modo se apresentam as práticas de leitura dos estudantes que participaram da pesquisa. Assim, temos que os alunos de ambos os anos escolares leem em mesma escala, sendo a leitura escolar a mais frequente, como pode ser visto no Gráfico 3, que segue: 
V. $10(2)$ $1-24$ maio-ago 2020
Gráfico 3 - Frequência diária de leitura

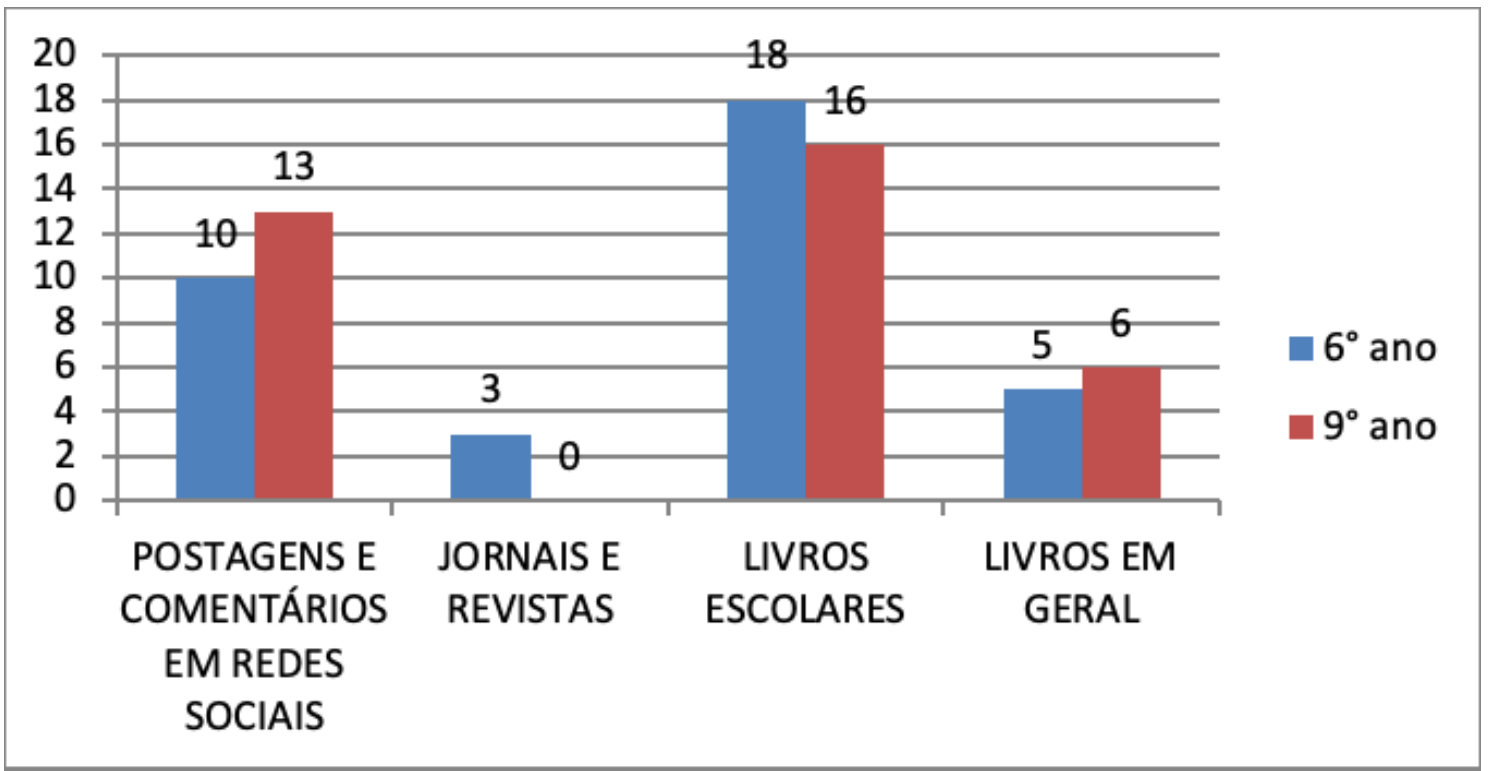

Fonte: Elaborado pelos autores.

Outrossim, quando concentramos nossa análise no concernente a "que tipo de leitura esses estudantes estão realizando?", vemos que a leitura em redes sociais se apresenta superior quando comparada à leitura de livros de uma forma geral. Não podemos descartar, contudo, que esse é um gráfico que julga a leitura diária e que alguns estudantes optaram pela opção "livros em geral" na categoria "semanal".

Uma vez que "os problemas de leitura radicam em problemas mais ou menos subtis [sic] de linguagem" e "que os maus leitores apresentam défices de linguagem" (VIANA, 2002, p. 22), consideramos que os estudantes dessa escola, em sua parcela majoritária, leem de forma propícia para um bom desempenho linguístico, o que se reflete nos nossos resultados, uma vez que o número de apagamentos foi menor do que o esperado, tendo em vista que não chegou nem mesmo a $8 \%$ na turma do $9^{\circ}$ ano.

Ainda tendo em vista que os resultados obtidos por essa pesquisa demonstram um número razoável do fenômeno linguístico aqui abordado, esse fato não anula a sua presença nos textos dos escreventes.

\section{Considerações finais}

Alinhando-nos à perspectiva da sociolinguística educacional (cf. BORTONI-RICARDO, 2002) e tendo em vista que há: 
uma formulação geral com diretrizes que incorporam o estudo de variação linguística entre os temas do ensino de português e situam o trabalho com a expressão culta no interior do quadro mais amplo da variação linguística que caracteriza a nossa sociedade. (FARACO, 2015, p. 20)

Visamos, com esta pesquisa, nos ater aos fatores responsáveis pelo processo de apagamento do rótico em posição de coda silábica em ambiente escolar. Assim, foi possível aprofundarmo-nos no fenômeno aqui estudado, obtendo dados mais próximos à realidade local, comprovando, por exemplo, que há vazamento linguístico do campo fonético para a escrita no concernente ao apagamento do rótico. Acreditamos que essa seja a justificativa para essa ação, já que a língua é heterogênea e não há como escapar a certos processos de variação, como este, por exemplo, visto que obtivemos um percentual de apagamento do rótico de aproximadamente $22,27 \%$ só no $6^{\circ}$ ano do EF II, dado que reflete, em certa medida, o fenômeno de apagamento já comprovado na oralidade por outros autores (cf. VEGINI, 2007; CARDOSO et al., 2014).

Outrossim, compreendendo que "a variação, embora aparentemente caótica e aleatória", pode "ser prevista e sistematizada" (TASCA, 2002, p. 17), colocamos nossos resultados em contraste com os obtidos por outros pesquisadores em investigações anteriores. Desse modo, as análises feitas nos permitem postular que os casos de apagamento tendem a diminuir com o avanço do nível de escolaridade, posto que o percentual de apagamento reduziu para $\cong 7,95 \%$ no ano final do EF II ( $9^{\circ}$ ano); conjecturamos, ainda, que palavras que são de vocabulário familiar aos escreventes tendem a anular o fenômeno do apagamento.

Seguindo, concluímos que a classe gramatical que se apresentou mais propícia para o apagamento foi a de verbos; no entanto, torna-se válido destacar que foi também a classe que apresentou melhor evolução. Curiosamente ao resultado anterior, o fenômeno de apagamento ocorreu em maior frequência na posição de coda medial. Por fim, foram verificados casos recorrentes em que aconteceram o processo de hipercorreção; como por exemplo "percevejo", pois foi significativo o número de alunos que a grafaram com dois erres, um contexto de hipercorreção que não estava previsto inicialmente.

De mais a mais, os baixos índices de apagamento encontraram justificativa nos frequentes hábitos de leituras dos estudantes que participaram dessa pesquisa, tendo em vista que os "erros" ortográficos 
V. $10(2)$ $1-24$ maio-ago 2020

são mais comuns em aprendizes que praticam pouca leitura, como apreciado na seção referente às práticas de leitura e sua participação no processo de aquisição da escrita ortográfica.

\section{Referências}

ALVARENGA, D.; OLIVEIRA, M. A. Canonicidade silábica e aprendizagem da escrita. Rev. Est. Ling., Belo Horizonte, ano 6, n. 5, v. 1, p. 127-158, jan./jun. 1997.

BISOL, L. Introdução a estudos de fonologia do português brasileiro. Porto Alegre: EDIPUCRS, 2009.

BORTONI-RICARDO, S. M. Educação em língua materna: a Sociolingüística na sala de aula. 4. ed. São Paulo: Parábola Editorial, 2004.

CAGLIARI, L. C. Questões de morfologia e fonologia. Campinas: [s. n.], 2002.

CALLOU, D.; MORAES, J.; LEITE, Y. Apagamento do R Final no Dialeto Carioca: um Estudo em Tempo Aparente e em Tempo Real. DELTA, São Paulo, v. 14, 1998.

CARDOSO, S. A. M. da S. et al. Atlas Linguístico do Brasil. Vol. 2. Londrina: EDUEL, 2014.

CORREAA, M. L. G. Letramento e heterogeneidade da escrita no ensino de português. In: SIGNORINI, I. (Org.). Investigando a relação oral/escrito e as teorias do letramento. São Paulo: Mercado das Letras, 2001. p. 135-165.

COSTA, G. B. da. Reflexões sobre o apagamento do rótico na escrita das séries iniciais. Revista Philologus, Rio de Janeiro, n. 45, p. 137-145, set./dez. 2009.

FARACO, C. A. Ensinar $x$ Não ensinar gramática: ainda cabe essa questão? Calidoscópio, [S. l.], v. 4, n. 1, p. 15-26, jan./abr. 2006.

FARACO, C. A. Norma culta brasileira: construção e ensino. In: ZILLES, A. M. S.; FARACO, C. A. (Orgs.). Pedagogia da variação linguística: língua, diversidade e ensino. São Paulo: Parábola Editorial, 2015. p. 19-30.

GARCIA, D. de J. A influência da oralidade na escrita das séries iniciais: uma análise a partir de erros ortográficos. 2010. Dissertação de Mestrado (Programa de Pós-Graduação em Educação) - Universidade Federal de Pelotas, Pelotas, 2010. $100 \mathrm{f}$.

MASSINI-CAGLIARI, G. "Erros" de ortografia na alfabetização: Escrita fonética ou reflexões sobre o próprio sistema de escrita? In: MASSINI-CAGLIARI, G.; CAGLIARI, L. C. Diante das letras: A escrita na alfabetização. Campinas: Mercado de Letras, 1999. p. 121-128.

LABOV, W. Padrões Sociolinguiísticos. Trad. Marcos Bagno, Maria Marta Pereira Scherre, Caroline Rodrigues Cardoso. São Paulo: Parábola, 2008.

MIRANDA, A. R. M. Aspectos da escrita espontânea e da sua relação com o conhecimento fonológico. In: $\mathbf{7}^{\mathbf{0}} \mathbf{E N A L}$ - Encontro Nacional Sobre Aquisição 
da Linguagem: Simpósio: Revisitando aspectos da aquisição da escrita: consideraçōes linguísticas. Rio Grande do Sul: PUCRS, 2006.

MOLLICA, M. C. Da linguagem coloquial à escrita padrão. Rio de Janeiro: 7Letras, 2003.

MOLLICA, M. C. Fala, letramento e inclusão social. São Paulo: Contexto, 2007.

MONARETTO, V. N. O. A vibrante pós-vocálica em Porto Alegre. In: BISOL, L.; BRESCANCINI, C. (Orgs.). Fonologia e variação: recortes do português brasileiro. Porto Alegre: EDIPUCRS, 2002.

MONARETTO, V. N. O. Descrição da vibrante no português do sul do Brasil. In: BISOL, L.; COLliSCHONN, G. (Orgs.). Português do Sul do Brasil: variação fonológica. Porto Alegre: EDIPUCRS, 2009. p. 141-151.

RIBEIRO, L. N. de S. 0 apagamento do -R em posição de coda silábica: há influência da fala na escrita discente? Dissertação (Mestrado em Estudo de Linguagens) - Universidade do Estado da Bahia, Salvador, 2013.

SENE, M. G. de; ORANGES, C. S. Fala [ $\varnothing]$ e escreve [ $[$ ]: variação do rótico em posição de coda na escrita escolar de Uberaba/MG. Entrepalavras, Fortaleza, v. 7, p. 165-181, jan./jun. 2017.

SGARBI, N. M. F. de Q.; RONCÁLIA, F. de L. Sociolingüística educacional: teoria e prática nas aulas de língua portuguesa. InterLetras, Dourados - MS, v. 2, ed. 10, jul./dez. 2009.

TASCA, M. Interferências da língua falada na escrita das séries iniciais: $O$ papel de fatores lingüísticos e sociais. Porto Alegre: EDIPUCRS, 2002.

TOLEDO, A. do R. A realização dos róticos em coda silábica na cidade de Paranaguá - litoral do Paraná. SIGNUM: Est. Ling., Londrina, v. 12, n. 1, p. 403-422, jul. 2009.

VEGINI, V. As realizações dos róticos no português brasileiro: um recorte fonoestilístico. Revista Virtual de Estudos da Linguagem - ReVEL, V. 5, n. 9, ago. 2007.

VIANA, F. L. Melhor falar para melhor ler: um programa de desenvolvimento de competências linguísticas 4-6 anos. 2. ed. Braga: Centro de Estudos da Criança da Universidade do Minho, 2002. 
V. 10 (2) 1-24 maio-ago 2020

\section{Apêndices}

Apêndice A - Ditado de frases

1) $O$ da menina quebrou.
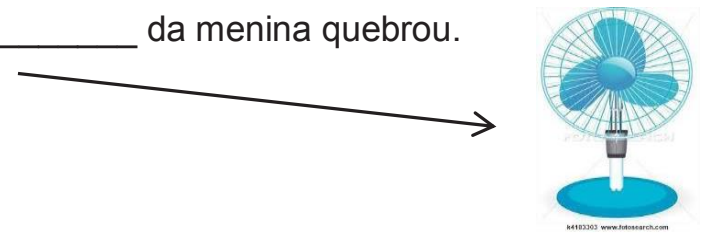

2) $\mathrm{O}$ chegou à igreja.

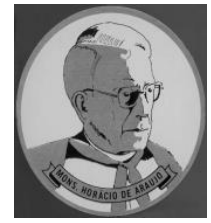

3) A garota foi à praia e levou o solar.
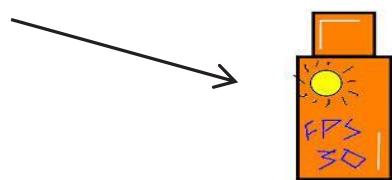

4) A menina foi se com o padre.

5) $\mathrm{O}$ foi para a floresta.

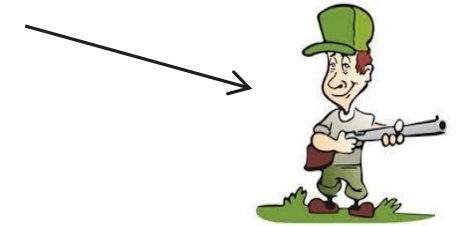

6) A garota ganhou um de presente do papai.

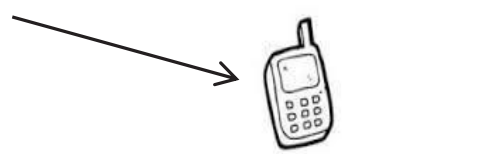

7) O casal de idosos saem juntos para
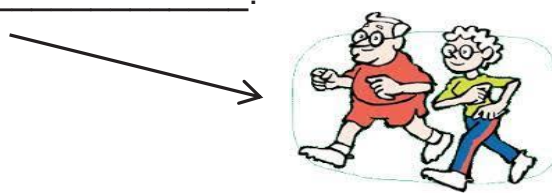
8) O menino adora cartas para a vovó.

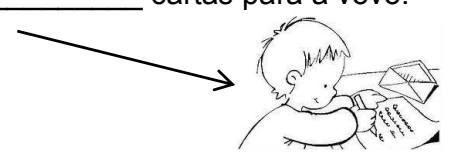

9) $\mathrm{O}$ limpou e arrumou a sala de aula.

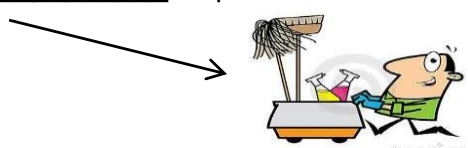

10) A garotinha foi tomar com a vovó.

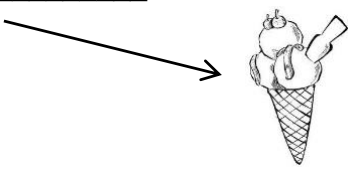

11) $\mathrm{O}$ invadiu a casa de Lulu.

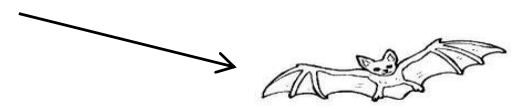

12) O jovem precisou sua mala rapidamente.

13) A menina passou a

da ajuda da família para se recuperar.
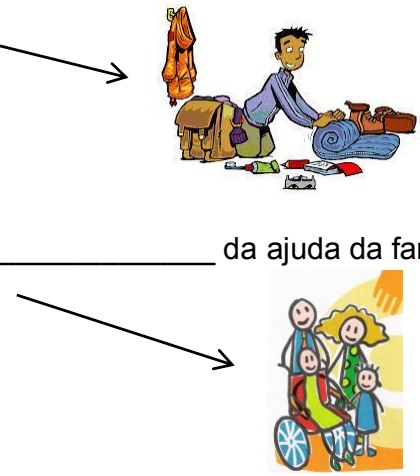

14) A planta estava repleta de

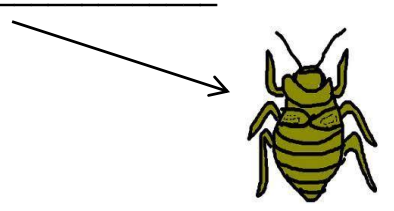




\section{10 (2)} $1-24$ maio-ago 2020

15) A professora ensinou aos alunos que é preciso o meio ambiente.
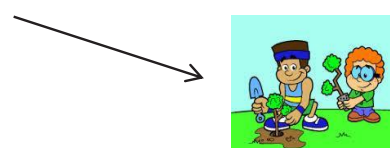

16) O Bob Esponja é um muito amado pelas crianças.

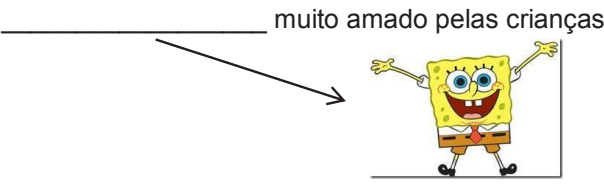

17) Os fantasmas foram o sono de Lulu.

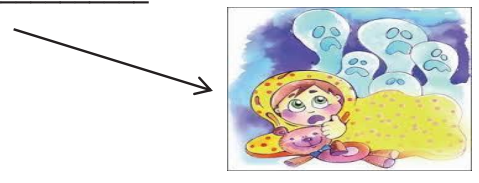

18) A garota passou a com atenção.
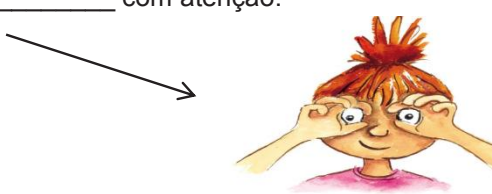

19) A esposa que o marido estava preocupado.

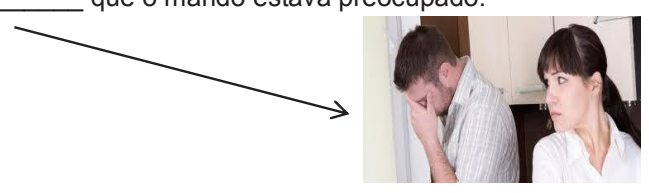

20) A mãe deu Sustagen Kids ao filho para os ossos do menino.

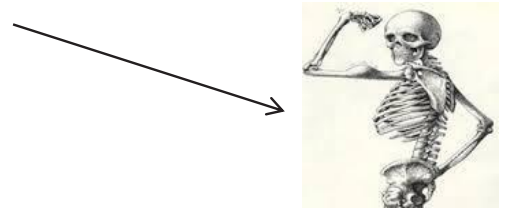




\section{Apêndice B - Questionário}

Nome:

Sexo: ( ) FEMININO

( ) MASCULINO

Idade: anos.

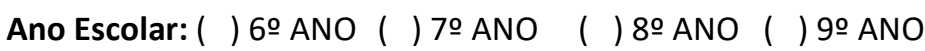

\section{QUESTIONÁRIO - HÁBITO DE LEITURA}

\section{Responda quanto a sua frequência de leitura:}

- Postagens e Comentários em Redes Sociais, Blogs e Sites:

( ) Diário ( ) Semanal ( ) Mensal ( ) Anual ( ) Nunca/Raramente

- Jornais e Revistas

( ) Diário ( ) Semanal ( ) Mensal ( ) Anual ( ) Nunca/Raramente

- Livros Escolares

( ) Diário ( ) Semanal ( ) Mensal ( ) Anual ( ) Nunca/Raramente

- Livros em Geral

( ) Diário ( ) Semanal ( ) Mensal ( ) Anual ( ) Nunca/Raramente

2. Quais são os assuntos que você mais gosta de ler?

3. Você costuma ler textos/imagens impressas ou em formato digital?

( ) Impresso ( ) Digital

4. Por que você escolheu a opção acima?

5. Você considera que o seu tempo dedicado à leitura é:

( ) Suficiente ( ) Insuficiente

10. Quais destes problemas te impedem de ler mais?

( ) Tempo ( ) Condições Financeiras ( ) Dificuldade de acesso à uma biblioteca

( ) Lentidão na leitura ( ) Outro:

\section{Onde geralmente você lê mais?}
( ) Em casa
( ) Na Escola

7. Você gosta de ler?
( ) Sim
（） Não 
V. $10(2)$

$1-24$

maio-ago

2020

\section{QUESTIONÁRIO - HÁBITO DE ESCRITA}

8. Responda quanto a sua frequência de escrita:

- Postagens e Comentários em Redes Sociais, Blogs e Sites:

( ) Diário ( ) Semanal ( ) Mensal ( ) Anual ( ) Nunca/Raramente

- Aplicativos de Mensagens

( ) Diário ( ) Semanal ( ) Mensal ( ) Anual （） Nunca/Raramente

- Diário Pessoal

( ) Diário ( ) Semanal ( ) Mensal ( ) Anual ( ) Nunca/Raramente

- Outros:

( ) Diário ( ) Semanal ( ) Mensal ( ) Anual ( ) Nunca/Raramente

9. Quais são os assuntos que você mais gosta de escrever?

10. Você costuma escrever em suportes físicos (papel) ou digitais (sites / blogs / redes sociais)?

( ) Físico ( ) Digital

11. Por que você escolheu a opção acima?

12. Você considera que o seu tempo dedicado à escrita é:

( ) Suficiente ( ) Insuficiente

13. Quais destes problemas te impedem de escrever mais?

( ) Tempo ( ) Condições Financeiras ( ) Dificuldade de acesso à uma biblioteca

( ) Dificuldade com as regras gramaticais ( ) Outro:

14. Onde geralmente você escreve mais?

( ) Em casa ( ) Na Escola

15. Você gosta de escrever?

( ) Sim ( ) Não 